\title{
Using Seasonal Climate Forecasts to Guide Disaster Management: The Red Cross Experience during the 2008 West Africa Floods
}

\author{
Arame Tall, ${ }^{1,2}$ Simon J. Mason, ${ }^{3}$ Maarten van Aalst, ${ }^{2}$ Pablo Suarez, ${ }^{2}$ \\ Youcef Ait-Chellouche, ${ }^{4}$ Adama A. Diallo, ${ }^{5}$ and Lisette Braman ${ }^{2,3}$ \\ ${ }^{1}$ Johns Hopkins University School of Advanced International Studies (SAIS), 1717 Massachusetts Avenue, N. W., \\ Office 715, Washington, DC 20036, USA \\ ${ }^{2}$ Red Cross/Red Crescent Climate Centre, The Hague, The Netherlands \\ ${ }^{3}$ International Research Institute for Climate and Society (IRI), Palisades, NY, USA \\ ${ }^{4}$ UNISDR Africa Regional Office, Nairobi, Kenya \\ ${ }^{5}$ African Center for Meteorological Applications to Development (ACMAD), Niamey, Niger
}

Correspondence should be addressed to Arame Tall, arametall@gmail.com

Received 29 September 2011; Revised 22 December 2011; Accepted 15 January 2012

Academic Editor: Gregory S. Jenkins

Copyright () 2012 Arame Tall et al. This is an open access article distributed under the Creative Commons Attribution License, which permits unrestricted use, distribution, and reproduction in any medium, provided the original work is properly cited.

\begin{abstract}
In 2008, the seasonal forecast issued at the Seasonal Climate Outlook Forum for West Africa (PRESAO) announced a high risk of above-normal rainfall for the July-September rainy season. With probabilities for above-normal rainfall of 0.45 , this forecast indicated noteworthy increases in the risk of heavy rainfall. When this information reached the International Federation of Red Cross and Red Crescent Societies (IFRC) West and Central Africa Office, it led to significant changes in the organization's flood response operations. The IFRC regional office requested funds in advance of anticipated floods, prepositioned disaster relief items in strategic locations across West Africa to benefit up to 9,500 families, updated its flood contingency plans, and alerted vulnerable communities and decision-makers across the region. This forecast-based preparedness resulted in a decrease in the number of lives, property, and livelihoods lost to floods, compared to just one year prior in 2007 when similar floods claimed above 300 lives in the region. This article demonstrates how a science-based early warning informed decisions and saved lives by triggering action in anticipation of forecast events. It analyses what it took to move decision-makers to action, based on seasonal climate information, and to overcome traditional barriers to the uptake of seasonal climate information in the region, providing evidence that these barriers can be overcome. While some institutional, communication and technical barriers were addressed in 2008, many challenges remain. Scientists and humanitarians need to build more common ground.
\end{abstract}

\section{Introduction}

1.1. West Africa's Vulnerability to Climate Shocks. Seasonalto-interannual variability of the climate system has major impacts on the populations of West Africa, one of the world's lowest-income regions. Here, $75 \%$ of the active population is employed in a rain fed agricultural sector [1], which is highly climate sensitive. Only 2 percent of the total cultivated land in West Africa is irrigated or under some other form of water management, the remaining $98 \%$ being rain fed [1]. In countries such as Niger or Burkina Faso, up to $92 \%$ of the active population is employed in the rain-fed agricultural sector [1]. A growing majority of the population also lives in ill-planned urban shantytowns built on flood plains where they settled during the prolonged Sahelian drought period from the early 1970s to the late 1980s [2,3]. The droughts drove peasants out of the countryside and into unplanned periurban settlements where functioning drainage systems are rare and so are vulnerable to flooding $[4,5]$. Fifteen of West Africa's seventeen countries lie at the bottom of the human development ladder, according to the United Nations Development Program Human Development Index ranking, and are classified among the twenty-two poorest countries in the world [6].

Against this context of high exposure to climate variability and low coping capacity, even slight changes in 
temperatures and expected rainfall patterns can affect vast numbers of vulnerable people. Thus, when natural hazards occur in the region, they tend to cause disasters that increase poverty further. Disasters result from the combination of naturally driven hazards, human-induced conditions of vulnerability, and insufficient capacity or measures to reduce the potential negative consequences of risk [7].

\subsection{Science-Based Forecasts to Benefit the Most Vulnerable.} The extreme vulnerability of West Africa to climate variability makes the region an ideal potential beneficiary of the type of seasonal climate information provided through the Regional Climate Outlook Forums (RCOFs; [8]). The Prévisions Saisonnières en Afrique de l'Ouest (PRESAO), West Africa's Seasonal Outlook Forum, was established in 1998 and has occurred annually each May to provide a consensus forecast for the coming July-September rainfall season. The PRESAO brings together scientists and hydrologists from National Meteorological and Hydrological Services (NMHSs), and regional and international climate centers to discuss and agree on the forecast for the JulyAugust-September (JAS) rainy season over West Africa. This consensus-based forecast issued at the end of the PRESAO forum is considered an authoritative voice on conditions most likely to prevail over the upcoming JAS season in West Africa, Cameroon, and Chad.

In the past, seasonal forecasts have been underutilized for many reasons. Institutionally, there had been no sustained dialogue between climate institutions and humanitarians in the region in the past. Culturally, a shift was needed from a mindset of disaster response to one of preparedness and early action. Financially, convincing donors to fund preparedness activities for predicted events that were only probable, not certain, was a challenge. Technically, information provided by meteorologists was largely incomprehensible to the regional decision maker/disaster manager/Red Cross volunteers. Scientifically, the information was often not salient to the latter's information needs and was given in terms of probabilities to reflect uncertainty inherent in the forecast, requiring new strategies for taking decisive action.

Not unique to West Africa, this disconnect between forecasters and humanitarians partly explains why vulnerable populations worldwide continue to be impacted by predictable natural hazards, as illustrated, for instance, by the 2005 famine in Niger, cyclone Nargis in Myanmar, and hurricane Katrina in the United States [9]. Despite the significant potential of early information about likely climatic hazards to aid vulnerable groups in better coping with climate variability, save lives, and preserve livelihoods in this highly climate-sensitive region, across Africa there are only a few haphazard instances of successful transmission and use of available climate and weather forecasts, and other climate risk management tools by policy makers and communities at risk.

1.3. Challenges to the Uptake of Seasonal Climate Information in Africa. Regional climate outlook forums (RCOFs) are the chief means through which seasonal climate forecasts are developed for subregions within Africa. RCOFs are held on an annual or biannual basis in advance of the rainy season, with the seasonal forecast usually developed for a 90-day climate window and at national or regional scales. Forecasts are expressed in probabilistic terms, reflecting the likelihood of below-normal, normal, or above-normal rainfall. Following the rainy season, some simple verification analyses are performed, but end-user communities are typically not included in retrospective analyses to understand the use and value of preseason information.

The top-down information flow that characterizes the RCOF process tends to preclude input from intended beneficiaries as to how forecasts can best be translated to address specific societal needs, or how to develop knowledge packages that bundle climate predictions with information about appropriate remedial actions or other livelihood priorities [10-12]. This reliance on RCOFs as the predominant vehicle for seasonal forecast dissemination has proven inadequate for reaching vulnerable populations and being integrated into their decision making processes [11].

Patt and Gwata [13] delivered seasonal forecasts to farmers in four villages in Zimbabwe, one in each of the country's four predominant natural regions, between 2000 and 2001. Their experience shows that the factors constraining use of the forecasts by the farmers include: (i) credibility (communities do not trust the message), (ii) legitimacy (lack of trust in the people who deliver the message, that is, the messengers), (iii) scale (the need for better geographic and temporal downscaling of region-wide seasonal forecasts), (iv) cognition (if users do not understand a forecast, they will not use it), (v) procedures (a forecast that arrives too late, after farmers have already purchased their crops and fertilizers for the season, is not salient to their needs), and (vi) choices (when forecast does not contain enough new information, decisions will not be changed based on a forecast).

Thus, the causes of limited dissemination and use of seasonal information across Africa appear to be as follows:

(a) lack of outreach to key stakeholders at the national and subnational levels, such as disaster management agencies, public health officials, community-based humanitarian organizations, and water managers, including vulnerable groups, such as urban slum dwellers, farmers, and fishermen; in line with the lack of outreach to key stakeholders, the inexistence of communication systems to communicate hazard alerts to communities at risk.

(b) poor interpretation and communication of forecasts;

(c) forecasts in their current form are insufficiently relevant to information needs and decision making timelines (non-salience);

(d) inability to act on forecasts;

(e) lack of trust in seasonal forecasts.

Can these systemic constrains to seasonal climate information use be overcome? If so, what is required to spur decision makers to action based on ex-ante seasonal predictions? 
In the following section, we review each of these constraints and then proceed to analyze the no-regret strategies carried out by the International Federation of Red Cross and Red Crescent Societies (IFRC) ahead of the 2008 floods in West Africa that substantially helped to address the constraints to seasonal forecast use for disaster prevention. These strategies included mobilizing funding ex-ante flooding occurrence, hiring an in-house intern to translate scientific seasonal climate information into lay language operational for decision making, prepositioning disaster relief items across the region in the likely event that the forecast materialized, securing partnerships with regional climate production centers, as well as training additional staff and communicating the seasonal forecast through trusted Red Cross branches and community volunteers at the national and subnational levels.

\section{Background: Constraints to Use of Climate Information}

2.1. Lack of Outreach to Key Stakeholders at the National and Subnational Levels. The content and process of existing climate information are not adequately designed to reach vulnerable groups dwelling at the most basic geographic levels, that is, villages or marginalized urban settlements $[4,14]$. Community radios constitute an effective means of reaching remote communities with information, but they are only seldom used to ensure that forecasts reach vulnerable communities in the region $[15,16]$. The lack of operational community-level relays of climate information, media outlets, and information-sharing systems that ensure the trickling down of climate information to the communities that most need it further constrains the ability of communities to access forecasts. For example, in Southern Africa, available forecast information does not specifically target vulnerable groups, and so the information either does not reach the community level at all or fails to reach the more marginalized groups $[10,17-20]$.

2.2. Poor Communication of Forecasts. Issues relating to language, content, and format of forecasts compound the poor accessibility of climate information. Indeed, these aspects of the forecast are not adequately considered to ensure forecast comprehension by community-level users [10, 14, 17, 19]. In Southern Africa, for example, very few NMHSs translate their forecasts beyond English, potentially excluding the most vulnerable yet important sectors of the target population (e.g., farmers, pastoralists, fishermen, and urban slum dwellers) from receiving and being able to use the forecasts [10]. Also, the probabilistic nature of seasonal forecasting is prone to misinterpretation and confusion if probabilities are translated into deterministic statements and warnings or are otherwise manipulated.

2.3. Nonsalience of Current Forecasts (Scientific Barrier). The current content and mode of climate information does not effectively address many of the concerns of community-level stakeholders, due to present limits in climate forecasting science. This lack of relevance, or specificity, in seasonal forecasts has multiple dimensions, including issues of poor spatial resolution of forecasts with respect to local-scale decision making needs, and an absence of information about intraseasonal rainfall distribution, as well as about climate parameters other than rainfall. Improving the local specificity of climate information in Africa will require greater investments in infrastructure to support hydro-meteorological applications. In Africa, the density of meteorological stations is about eight times lower than the minimum recommended by the World Meteorological Organization (WMO); many of these stations are nonfunctional and governments have failed to invest in equipment and trained personnel [21].

While rainfall is the chief concern for many end users, providing information about other climate parameters, such as relative humidity and temperature, would help countries to monitor soil moisture conditions in cropping areas and protect particular commodities, such as livestock, if temperatures exceed critical thresholds. For example, Ingram et al. [22] found that farmers in different agroecological zones in Burkina Faso were interested in receiving seasonal precipitation forecasts, but they were much more interested in receiving forecasts of when the rains would start and end, and whether there would be interruptions in rains.

Also related to insufficient forecast specificity is the apparent or potential lack of relevance of seasonal climate forecasts in some situations. For example, contradictions can exist between climatologically and agronomically optimal windows for seeding crops in high-risk farming environments. While the former relies on evidence from large-scale weather and climate dynamics to determine the "safe" start of the growing season, the latter considers effects of nitrogen leaching, weed competition, pest pressure, and seedling damage from heavy precipitation in deciding when to begin cultivation [23].

2.4. Low Capacity to Act on Forecasts. Climate information must compete with other livelihood demands, and while there may be sound climate-related reasons for heeding a forecast, there are often equally compelling reasons not to, particularly where resources or capacity are inadequate for effective action. The extent to which knowledge and information are acted upon at the local level depends upon perceptions of risk from current and future hydrometeorological hazards, as well as the influence that the array of nonclimate factors bring to bear on the risk calculus. Grothmann and Patt [24] describe how farmers in Zimbabwe, given a forecast of below-normal rainfall, still chose to grow maize over millet when the potential crop loss risks from drought were weighed against the substantial risks that might ensue from not growing maize, given the extent to which institutional, societal, and market forces were aligned in favor of maize production.

If farmers lack sufficient access to inputs, land, equipment and other capital, and credit, then they generally cannot effectively apply climate information, as in Southern Africa $[18,19]$. Similarly, in Burkina Faso, farmers need 
greater access to basic agricultural technologies, such as plows, new crop varieties, and fertilizers, before they could benefit fully from precipitation forecasts [15]. Bundling capacity building efforts for seasonal climate forecast use with timely access to credit or agricultural production inputs can help lower the threshold for acting on climate forecast information. The dissemination of the forecasts should be part of an extension package that includes a discussion of the probabilistic nature of the forecasts, potential response strategies, and risk management [22]. Social constraints, for example, the inability of younger decision makers to bypass family hierarchy in changing decisions about resource allocation and crop choice for a given season, can also constrain the ability to act on forecasts [15].

2.5. Lack of Trust in the Forecasts. Before communities can absorb incoming scientific information, trust needs to be built because acting on the information could mean shifting decisions and making costly, high-risk investments. Caution is justifiable given the marginality of household resources within many vulnerable communities. Building a trusting relationship between communities at risk from climate hazards and forecasters (or their messengers) is of central importance in understanding whether community-level decision makers will use received forecasts or not. One way to instill understanding of and trust in climate information is through the use of participatory workshops designed to help farmers and other target groups to better understand and use seasonal climate forecasts [22]. These workshops can improve trust and credibility of forecasts and provide an opportunity for farmers to experience repeated exposure to and become familiar with the concepts behind probabilistic forecasting, thus allowing better comprehension of what forecasts can and cannot do. Workshop participation can positively influence the anticipatory behavior of participants, through broadening their perceived range of options for the coming cultivation season, and the workshops provide spillover effects to the larger community as participants share information with nonparticipants.

An example from Mali illustrates well the importance of participatory processes in communicating climate information to community-level stakeholders. The Direction Nationale de la Météorologie du Mali, the country's NMHS, has been transmitting detailed agrometeorological information to groups of farmers since 1983. They have found that the participatory processes developed to provide agrometeorological advice to farmers have aided understanding of how to provide the information in a comprehensible and suitable manner, such that it is congruent with traditional practices or agricultural calendars [16]. Forecasters at Mali's national meteorological agency found that they could not hold stakeholder meetings in all the villages where demand for agrometeorological advice was increasing, so they gradually scaled up the project while heavily relying on rural radios and dispensing advisories for wider regions and for each different crop type.

Figure 1 summarizes the bottlenecks that have traditionally constrained the use of climate forecasts in Africa, and

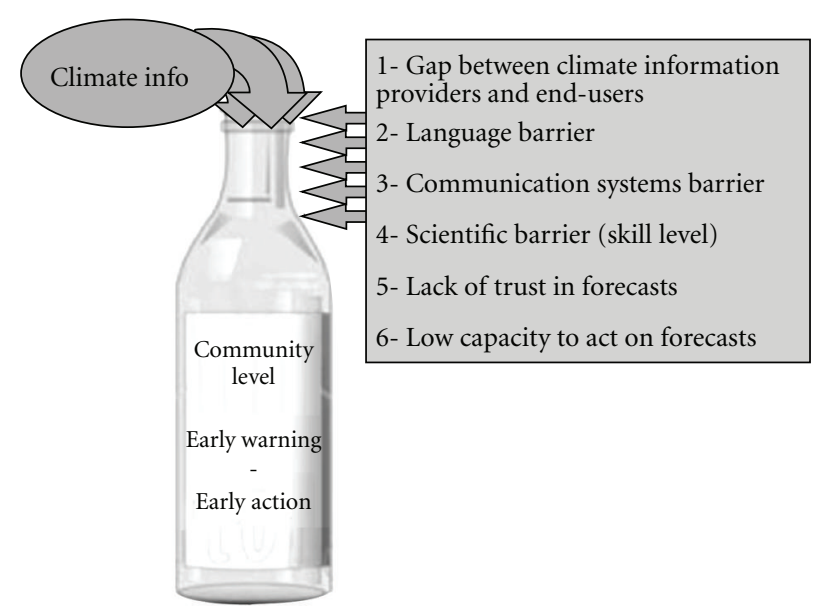

FIGURE 1: The bottlenecks to climate information access and use by vulnerable communities in West Africa (source: [14]).

their trickling down to communities most at risk. Despite these barriers to the use of climate information, in 2008, the seasonal forecast for West Africa was utilized by a regional humanitarian organization, the IFRC office of West and Central Africa, to plan its disaster response operations for the flood season, and as a result, lives and livelihoods were preserved in the region. In the next sections of this paper, we attempt to understand what changed in 2008 to enable the use of seasonal forecast information by a decision maker in the region, and how this year differed from just a year prior when flood disasters affected West Africa.

\section{Methods}

In order to understand the processes that triggered IFRC's utilization of the 2008 seasonal forecast, we undertook a number of process tracing steps. Firstly, we compared IFRC's disaster management strategies in 2008 with those in 2007, when the signals of probable flood conditions were not used to trigger preparedness measures. Secondly, we traced the processes that helped build capacity within IFRC (the largest humanitarian organization in the world), and particularly in its West and Central Africa Zone Office (WCAZ) to understand and use of science-based forecasts leading up to 2008. Then, through interviews with all of the actors involved in IFRC WCAZ's 2008 disaster management process, we proceeded with an events analysis of the organization's disaster preparedness and planning before the flood season in 2008 in West Africa, including the forecast-based decisions made by the IFRC-WCAZ. Finally, reports and news clips enabled the characterization of the final outcome of the 2008 rainy season, as well as the analysis of the achievements, and limitations, of IFRC's forecast-triggered disaster risk management strategies.

\section{Results}

4.1. IFRC's Disaster Management Strategy in 2007: ScienceBased Warning + Inaction = Avoidable Losses. In 2007, 
a seasonal forecast from the PRESAO (Figure 3) indicated enhanced probabilities of heavy rainfall, notably,

(i) in the far west region of West Africa, straddling Southern Chad, northern Cameroon and Nigeria, and Eastern Niger (where above-normal rainfall was the most likely outcome with a probability of 0.5 );

(ii) an equal likelihood of normal and above-normal rainfall conditions throughout the rest of the Sahel, with associated probabilities of 0.4 and 0.4 ;

(iii) most likely normal conditions only in the Gulf of Guinea countries, with a probability of occurrence of 0.5 [27].

When the forecast above-normal rainfall conditions did indeed materialize and severe floods occurred, the humanitarian community responded in emergency response mode, lacking advance knowledge on when and where floods were more likely to occur. The 2007 floods claimed more than 300 lives across West Africa and occasioned severe damage to crops, homes, and infrastructure [28].

The Red Cross did not access the PRESAO forecast in 2007 or during previous years, due to the weak-to- non-existent communication lines between climate forecasting centers (at the regional and national levels) and the Red Cross presence in the region (regional-level disaster planners and community-level volunteers). On the one hand, regional climate forecasting institutions such as the African Centre of Meteorological Applications for Development (ACMAD) and AGRHYMET, the regional authority for meteorological applications to food security, duly produced their forecasts and sent them to their national relays: NMHSs. On the other hand, the Red Cross continued to respond to weather-related disasters as it had always done, not using existing climate information-which they often did not know existed-as input into their decision making and contingency planning at the onset of the rainy season.

Natural hazards thus consistently became disasters despite the fact that (a) scientists in the region could anticipate their likely occurrence and (b) the humanitarian sector, and the people they serve, had the capability to act on the ground to thwart losses. The early warning was not turned into early action.

\subsection{Building Capacity within IFRC-WCAZ to Understand and} Use Science-Based Forecasts. Over the last few years, various processes contributed to improving the Red Cross' capability to link climate science with humanitarian work. These were encouraged by a growing momentum at the global level within the IFRC to build preparedness in the face of the humanitarian challenges of climate change, and included the following.

4.2.1. Growing Role of Climate Information in the Red Cross/Red Crescent Movement. In a context of changing climate risks, the Red Cross/Red Crescent Climate Centre was created in 2002 with the mission of supporting the Red Cross and Red Crescent movement to understand and address the humanitarian consequences of climate change and extreme weather events. The Centre's main approach is to raise awareness, advocate for climate adaptation and disaster risk reduction, and integrate knowledge of climate risks into Red Cross Red Crescent strategies, plans, and activities. By 2008, a total of 39 Red Cross/Red Crescent national societies, including 14 from Africa, had joined the "Preparedness for Climate Change" program. Instead of only focusing on climate change information based on scenarios for the end of the century, the program emphasized the need to link with forecast providers to improve decisions on all timescales and at various geographic levels from continental to community level.

In 2007, the 30th International Conference of the Red Cross and Red Crescent (its highest governing body, comprised of 186 national societies and national governments) committed to improve capacity to respond, including through better disaster preparedness, and to integrate climate risk management into policies and plans. Such high-level commitment enabled an easier uptake of offers to explore options for forecast-based humanitarian decisions. The disaster management coordinator for IFRC West and Central Africa Zonal Office attended and organized various workshops co-organized by the Climate Centre aimed at integrating climate science into disaster risk management.

4.2.2. First Steps in Science-Humanitarian Dialogue in West Africa. Three noteworthy changes occurred in 2008 to initiate a dialogue between Red Cross staff and climate forecasters, and to enable the transmission and use of the 2008 forecast.

(i) A new partnership between the IFRC and the International Research Institute for Climate and Society (IRI) at the global level enhanced the capacity of the humanitarian organization to understand sciencebased forecasts. Through this partnership, the IFRCWCAZ office was provided with ready access to expertise that could explain and interpret climate information. A help desk was established that allowed for timely and reliable responses to questions about forecasts or recent climate anomalies, and an intern went to the IFRC-WCAZ in the summer of 2008 to assist disaster managers in better understanding and incorporating climate information into disaster planning.

(ii) In 2008, the Red Cross Disaster Management Coordinator for West and Central Africa became enthusiastic on initiating a dialogue with climate scientists regionally and attended the PRESAO-11, the first time a disaster manager attended this scientific forum. Building on this initial outreach, IFRC-WCAZ spearheaded a drive for more outreach to the climate science community.

(iii) The severity of the 2007 floods, and memory of the frenzied response operations that followed, put Red Cross disaster planners in a favorable disposition towards increased preparedness. 
When the 2008 seasonal forecast reached the IFRC-WCAZ and warned of a heightened risk of above-normal rainfall, and this information was translated into language that they could understand, Red Cross disaster managers set in motion early action strategies that appear to be common sense but had never been implemented in the past.

\subsection{The 2008 Seasonal Forecast}

4.3.1. Contents of the Consensus-Based Forecast: Cause for Concern. In May 2008, the consensus-based forecast issued at the end of the PRESAO announced that the JAS rainy season over West Africa had enhanced probabilities of abovenormal rainfall, implying that the region was likely to experience increased risk of heavy rainfall events [25]. The PRESAO forecast, issued on May 21st 2008 by ACMAD, indicated increased probabilities for higher than normal rainfall throughout much of the Sahel belt from Senegal to Cameroon (probabilities of 0.45 and 0.50 in zones I and II, respectively; see Figure 2). Against a historical probability of 0.33 , these probabilities for above-normal rainfall were unusually high, and warranted heeding.

An updated seasonal climate forecast issued by ACMAD on June 27th re-affirmed the forecast issued a month earlier of high probabilities of rainfall higher than normal, and very low probabilities of below-normal rainfall over the region. ACMAD concluded its seasonal forecast update by stating that if forecast conditions persisted, the risk for flood disasters and water-related diseases could be higher than usual this year, requiring "strengthened weather watch, monitoring, and warning" for sectors like health, food security, water resources, and civil protection [25].

The International Research Institute for Climate and Society (IRI) seasonal precipitation forecast for Africa for the July-September period echoed the same warnings, indicating probabilities for above-normal rainfall for July-September similar to those of the PRESAO forecast, albeit differences in the geographic area at risk at the northern and southern frontiers of the Sahel and in months covered. The IRI forecast map for extreme seasonal rainfall (more than the 85th percentile) for June-August gave an even stronger message, signaling Senegal, the Gambia, and neighboring countries, as the only areas in the world with "highly enhanced" probabilities of rainfall extremes (see Figure 3 ).

As of May 2008, all the main sources (national, regional, international) provided a unanimous message that most parts of West Africa were more likely to experience higher than usual rainfall over the upcoming season. Although all these seasonal forecasts referred explicitly only to the seasonally integrated rainfall, and not to individual heavy rainfall events that are the primary cause of flooding, it is reasonable to assume that the actual risk of flooding will increase during a year in which the total rainfall is expected to be unusually high. (Further research on the extent to which this assumption is valid is clearly warranted.)

4.4. Communication of the Forecast to IFRC-WCAZ. When the seasonal forecast reached the IFRC Regional Office in

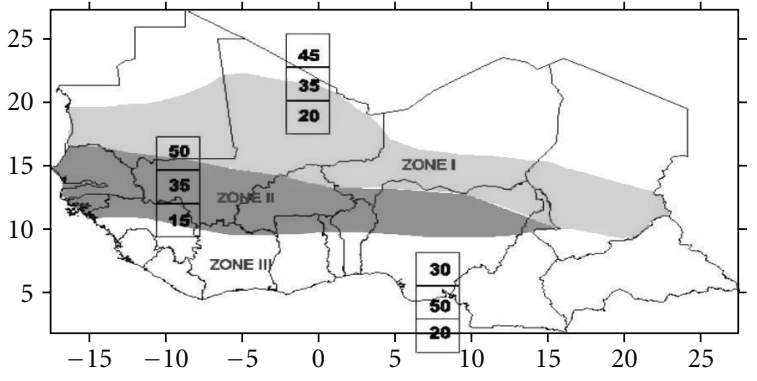

Figure 2: The 2008 PRESAO forecast: Probability forecast for precipitation over July-August-September (source: [25]).

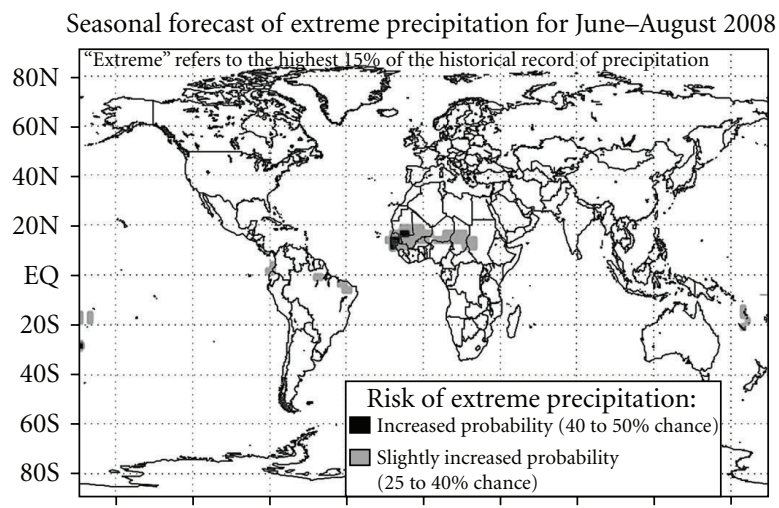

FIGURE 3: World areas likely to be at risk of "extreme" precipitation in the JJA season (source: [26]).

Dakar, the first challenge consisted of helping decision makers at IFRC-WCAZ understand the contents and implications of the PRESAO forecast. The intern from IRI played an instrumental part in this assistance and served as in-house translator of the received seasonal forecast maps. The 2008 seasonal forecast map was largely incomprehensible to the IFRC regional disaster managers because of the technical language used, the absence of detailed, clear commentary, and the lack of clarity on how the forecast information might be relevant to their humanitarian work. To this effect, an all-staff climate briefing was organized in early June by the IFRC-WCAZ Disaster Management Unit to share the PRESAO forecast with all operational departments at IFRCWCAZ. During this briefing, Figures 3 and 4 were shown and explained by the intern.

Contrary to expectations, the probabilistic nature of the forecast did not pose any challenges to the Red Cross disaster planners; they welcomed it as an approximate answer to their question: whether or not disasters were going to occur. Even though it did not tell them with certainty whether disasters would be taking place, it still provided them with a rational and scientifically-informed process of making key planning and resource allocation decisions under uncertainty, one which was coherent with the way they usually operated. Indeed, as disaster planners, they were accustomed to preparing their relief interventions based on contingency plans and various scenarios for intervention at the beginning 


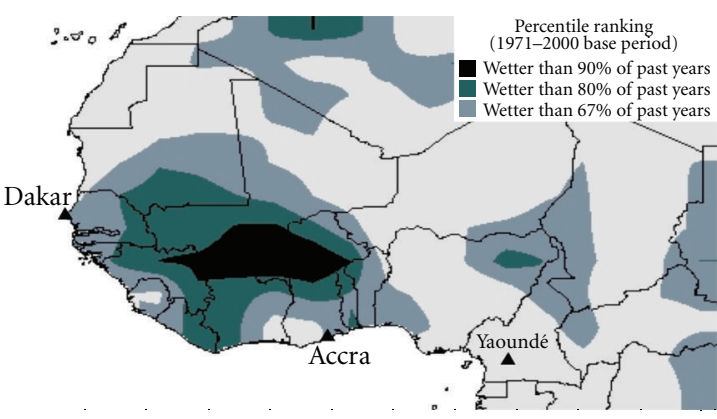

FIGURE 4: Observed rains and location of stocks prepositioned by IFRC in June-August 2008, represented by triangles (source: authors).

of the rainy season. In the past, however, none of these plans were informed by seasonal climate forecasts.

\subsection{Linking Early Warning with Early Action: Ex-Ante Fore- cast-Based Decisions Made by IFRC at the Regional Level}

4.5.1. First Pre-Emptive Appeal in IFRC History Based on a Seasonal Forecast. Based on the PRESAO seasonal JulySeptember 2008 and the IRI June-August seasonal forecasts, the IFRC drafted a zonal Flood Contingency Plan and issued a funding request to the Disaster Relief Emergency Fund (DREF), an internal Red Cross funding source. This appeal requested a total of CHF 298,376 (USD 284,167) in order to prepare for the heightened risk of floods in the region. The IFRC WCAZ explained in this request its worry that catastrophic floods were looming, drawing upon the ACMAD and IRI forecasts as its sources of information, explaining that while not certain the high probabilities still warranted action and advanced preparation was needed.

This DREF request was granted. A preliminary emergency appeal for flood preparedness in West and Central Africa was then issued on July 11th, requesting USD 730,000 in contributions from humanitarian donors to fund preparedness activities throughout the region [29]. Both PRESAO and IRI maps were again included in this appeal as justification for the need to get ready and prepare for forewarned floods. It was clearly explained therein that the forecasts were in terms of probabilities. This was the first time in the history of the Red Cross movement that funds were requested in advance to prepare for an emergency based on seasonal forecast information. It constitutes a positive instance of climate information duly transmitted and acted on.

Unfortunately, donors did not commit in time: funds from the preliminary appeal did not arrive until late August, after flood disasters were already underway. However, the IFRC-WCAZ was still able to use funds immediately available from the DREF to preposition emergency stocks in Dakar, Accra, and Yaoundé [30].

4.5.2. Prepositioning of Relief Items. Once funds were made available, the IFRC-WCAZ began the prepositioning of nonfood relief items (blankets, mosquito nets, soap, bottles, tents, etc.) in Dakar (Senegal), Yaoundé (Cameroon), and Accra (Ghana) to benefit up to 9,500 families in the event of flooding. Under a typical ex-post response scenario, these items would have been flown in from the IFRC's Dubai warehouse once floods arrived, or procured separately, leading to a more time-consuming and costly shipment of relief supplies.

This "no-regret" approach was the strategy used by IFRC-WCAZ to address the uncertainty inherent in the seasonal forecast. Indeed, by prepositioning only non-perishable items that could be reused during future flood events, disaster managers at IFRC-WCAZ were able to minimize their potential losses and justify their ex-ante use of funds without complete certainty of the occurrence of a disaster.

\subsubsection{Training of Additional Red Cross Disaster Management} Personnel. Following the forecast of a high-risk rainy season the IFRC-WCAZ trained in early July twelve leaders of Regional Disaster Response Teams (RDRTs), to be deployed to the field within 48 hours of a disaster in the region to coordinate relief operations and conduct a rapid assessment of damage and needs. These RDRT leaders were specifically trained in understanding medium-term weather forecasts accessible online via the IFRC's online Disaster Management Information System so that they would be able to monitor rainfall throughout the season, and write national flood contingency plans using real-time meteorological information. Additionally, at the end of the training, all RDRT leaders were provided with travel insurance (rendering them "deployable" within 24 hours of onset of a flood disaster in the region) and were asked to prepare a flood contingency plan for their respective countries, by July 15 th [31].

4.5.4. Partnerships with Regional Climate Centers. Finally, a significant achievement from the 2008 experience is the demand it created within IFRC-WCAZ for additional climate information. Building on this strong desire to reach out to regional climate research centers as a pathway to secure inflow of reliable and trustworthy climate information at the regional level, formal partnerships were initiated and put in writing in late July with both ACMAD and AGRHYMET. Throughout the 2008 rainy season, IFRC-WZAC reached out to these scientific partners, inquiring about likely atmospheric conditions in given countries and constantly requesting additional information to followup on the seasonal forecast. This process of interaction culminated in the signature of a Memorandum of Understanding between ACMAD and IFRC-WCAZ, the first ever partnership accord signed between climate scientists and humanitarians in the region.

4.5.5. Communication of the Forecast. Utilizing the Red Cross' extensive network of volunteers on the ground, the IFRC-WCAZ was able to share the seasonal rainfall forecast with countries and communities at risk throughout West Africa. By July, the seasonal forecast was received by all Red Cross National Societies deemed to be at potential risk from flooding during the July-September rainy season (countries 
located in Zones I and II, Figure 1). Varying levels of capacity of these national societies, however, hindered or facilitated the distribution of the forecast to local Red Cross branches at district and village levels. In many instances, Red Cross volunteers serving as community relays of forecast information were able to take the information to people at risk in effective ways, using distribution channels as innovative as transport buses (Togo Red Cross), cellular phone text messages (Burkina Red Cross), and word of mouth.

\subsection{Outcome of the 2008 Rainy Season: \\ Heavy Rains and Reduced Losses}

4.6.1. Rainfall during the 2008 Season. Heavy rainfall events occurred throughout the July-September rainy season in West Africa. Although the forecasts are probabilistic in nature and so cannot be properly verified considering only this single case, there are grounds for arguing that because the forecasts indicated high probabilities of above-normal rainfall, they were "good." The IFRC-WCAZ reinterpreted the forecast in terms of risk of flooding (associated primarily with individual heavy rainfall events) within the season rather than in terms of seasonal total rainfall, and so from their perspective, the season contained multiple verifications rather than a single one. In addition, for the advanced preparedness actions undertaken, precision in the location of areas of heavy rain was not necessary. The disaster managers were not concerned about whether such flooding would occur throughout the regions of increased probabilities of unusually large seasonal totals, but only that there would be an unusually large number of flooding events scattered somewhere within (or, for some decisions, somewhere near) the area of enhanced probabilities for a wet season.

Figure 4 depicts the locations of flood-related disasters requiring Red Cross intervention in West Africa during the 2008 rainy season and shows some geographical coherence with the seasonal forecasts: ten out of the twelve severe flood events that took place occurred in Zone I of the PRESAO forecast map, where above-normal rainfall had been predicted as the most likely outcome. Only two floods, in Togo and Cameroon, occurred in the Zone III Gulf of Guinea countries, where the probability for above-normal seasonal rains was close to climatology.

When the floods came, the Red Cross movement on the ground was already aware, informed, and ready to intervene, thanks to the preparedness measures endeavored by the IFRC Zone Office. These initiatives helped raise awareness at the national level in the countries at risk, where humanitarian actors were able to initiate national-level actions to prepare for likely flood events. In the words of Jerry Niati, Assistant Disaster Management Coordinator at the IFRC in Dakar "In 2007, we were just being asked to do things; in 2008, we were initiating action by raising awareness and sharing forecast information" [32].

4.6.2. Damage and Losses Reduced. A preliminary IFRC assessment of the results of having engaged in early action during the flood season 2008 concluded that after the initial region-wide preparations had been put in place, more direct action at the local level could be taken in response to shorterrange forecasts. Because of this early action, the following outcomes at national and community levels were possible.

(i) In Ghana, the Volta River Authority Power Company and its Burkinabe counterpart SANOBIL agreed upon a control regime to protect communities along the Black and White Volta Rivers during the 2008 rainy season. Volunteers of the Ghana Red Cross thus set out to advise fishermen not to go out on the river between August 21-23, the announced period of excess spillage from the Bagre Dam. These actions saved lives and reduced damage in August and September of that year compared t0 2007 [28].

(ii) In Togo, in response to the 2008 seasonal forecast, a communication system was established to enable the circulation of information from the national Red Cross society's headquarters, to contact focal points in the regions, districts, and communities at risk and back. In the community of Atiegou Zogbeji located north of Lomé, a community leader went through the flood-prone community with a loudspeaker when riverbed water levels reached dangerous levels asking people to evacuate [33]. With just an hour and a half's notice, the population of approximately 2000 was able to evacuate. When the floodwaters arrived, physical damage occurred, but no loss of life [28].

(iii) In response to being informed of the seasonal forecast and participating in the RDRT leaders' training, the Gambia held its own National Disaster Response Team (NDRT) training, in which volunteers and branch officers from seven different districts were trained in disaster preparedness. As a result of this training and preparation, the Gambia Red Cross proved very efficient in performing a postflood needs assessment and submitting a funding request within two days of flooding (a process which generally took them several weeks after the flood event).

Across the region in 2008, most countries received needed relief supplies from the Red Cross in a matter of days after the flooding. In contrast, the year before it took on average forty days to deliver many relief items and services. A preliminary quantitative comparison between the costs of flood response alone (2006 and 2007) and the cost of flood response with Early Warning-Early Action (2008) also showed a 33\% lower cost per beneficiary [28].

These assessments are only indicative, but they attest to the positive results that can be yielded when disaster planning is informed by climate science.

\section{Discussion: Towards Systematic Early Warning-Early Action in West Africa}

The Red Cross' 2008 experience with forecast-based disaster planning in West Africa clearly demonstrates the potential of climate forecasts to inform decision making and serve society. It also confirms all of the constraints identified by the 
literature that explain why forecasters and decision makers have not been collaborating with each other.

An analysis of the Red Cross' 2008 experience, however, reveals that a number of systemic elements can also serve to be instrumental to overcome these constraints. These are as follows (Table 1).

5.1. A Confident Forecast. Two positive attributes of the 2008 seasonal forecasts were particularly instrumental in polarizing the attention of Red Cross disaster planners and spurred them to action.

(1) The forecast was confident. The signal over West Africa in 2008 was strong enough that all the forecasting models under consideration indicated enhanced above-normal rainfall probabilities over most of West Africa. The agreement between the forecasts, combined with the strong message from the IRI "Extreme Precipitation" forecast map (Figure 4), was instrumental in making decision makers appreciate the level of urgency of the forecast.

(2) The forecast was timely. Following the attendance of the IFRC regional disaster manager to the PRESAO, the seasonal forecast was received by IFRC-WCAZ in late May, which gave one-month lead time to the humanitarian organization to trigger early preparedness actions (request funds for flood preparedness, inform communities at risk, train more disaster relief personnel, etc.).

5.2. The Use of "No-Regret" Strategies, a Useful Approach to Act on Probabilistic Forecasts. Events in 2008 evolved in line with the most likely scenario of above normal rainfall. However, the anticipated heavy rainfall could have failed to verify and events could have unfolded contrary to expectations. Indeed, there was still a 0.5 probability of normal or below-normal rainfall, combined, to occur in Zone II, and even higher probabilities in Zones I and III. Given the large inherent uncertainty in the seasonal forecasts, one positive strategy that the Red Cross adopted to address lingering uncertainty was to implement no-regret strategies. No-regret strategies consisted of actions and interventions that did not involve the commitment of resources to emergency relief goods or services that could go to waste if no floods materialized. These included prepositioning relief items that national Red Cross disaster managers could reuse during successive years if forecast floods did not occur in 2008, as well as capacity building and training of additional Red Cross community volunteers on first aid and disaster assistance procedures, needed in any case as part of the Red Cross' daily operations during peace as well as crisis time. In this sense, whether the most likely scenario forecast materializes or not, the situation that ensues is still a win-win from the standpoint of the decision maker committing resources on the basis of the forecast. This strategy of investing in noregret initiatives (which are beneficial even in the baseline without any disaster) is an effective win-win strategy to address the uncertainty inherent in climate forecasts.
5.3. Funding for Forecast-Based Early Action: A Challenge to Continued Use of Seasonal Forecasts to Trigger Emergency Preparedness. Expanded use of forecasts to trigger emergency preparedness will require that donors are willing to support such activities. Indeed, 2008 was the first time that a seasonalforecast-based flood preparedness appeal was issued, and given the novelty of the endeavor, the severity of the 2007 floods, as well as the urgency beckoned by the forecast, the IFRC Regional Office was able to request and secure some funds for preparedness. However, most of the limited funds only arrived when the floods were already underway.

The main reason explaining donors' slow response may be that forecast-based preparedness falls through the cracks of the two well-established disaster management funding channels that currently exist: (a) postdisaster work (response, recovery and reconstruction) and (b) long-term risk reduction work (often as part of regular development assistance). Most donor agencies lack mechanisms specifically designed to support humanitarian action based on forecasts on different timescales. Action based on forecasts may seem too emergency focused to justify funding through regular development assistance channels, but too early to warrant the use of disaster relief budgets, often perceived as being meant to relieve true human suffering once a disaster occurs.

Because of this gap between funding for relief and longterm risk reduction, there is a need for a dialogue between humanitarian organizations and donor agencies on how best to support forecast-based humanitarian action. Some have suggested that the new international climate change financing arrangements could play a role in filling that gap [34]. Such dialogues should be built on strong evidence on the potential benefits of forecast-based interventions, in terms of quality of humanitarian outcomes, and in terms of cost effectiveness of financing for humanitarian relief. Donors will probably not adequately support this early warning-early action approach unless they are provided with reliable, rigorous information proving how collaboration can lead to effective reduction of losses and/or more efficient use of scarce resources.

In 2008, the only truly rapid funding came from the Disaster Response Emergency Fund (DREF), a special mechanism dedicated for quick response before a full appeal is launched, for smaller disasters where no appeal may be issued at all, and to start humanitarian action for imminent (rather than only actual) disasters. Similar fund-based mechanisms perhaps specifically aimed at action based on probabilistic forecasts rather than at responding to single disasters seem to be a good vehicle for expanded forecast-based preparedness activities.

\subsection{Packaging and Content of Climate Information Unfit for} Community Decision Making. Save for the notable example of the community of Atiegou Zogbeji in Togo that evacuated in response to a flood early warning issued by the National Red Cross of Togo, the 2008 seasonal forecast did not contribute to trigger meaningful behavioral change beyond the regional and national levels. This is a conspicuous limitation of the 2008 use of seasonal climate information 
Table 1: Key Achievements, Limitations and Lessons learnt from the Red Cross' 2008 Early Warning-Early Action initiative in West Africa.

\begin{tabular}{|c|c|c|c|}
\hline Obstacle type & Achievements & Remaining obstacles & Recommendations \\
\hline $\begin{array}{l}\text { (1) Institutional (gap } \\
\text { between providers and } \\
\text { users of climate } \\
\text { information) }\end{array}$ & $\begin{array}{l}\text { Initiation of a dialogue between Red } \\
\text { Cross-West Africa and regional } \\
\text { climate providers (ACMAD, } \\
\text { AGRHYMET); formal partnership } \\
\text { established with ACMAD, securing } \\
\text { inflow of reliable climate } \\
\text { information (at the seasonal to } \\
\text { short-term timescales) }\end{array}$ & $\begin{array}{l}\text { Insufficient capacity in } \\
\text { humanitarian sector to provide } \\
\text { scientists with meaningful feedback } \\
\text { on how to tailor forecasts to } \\
\text { humanitarian needs. } \\
\text { No packaging of provided } \\
\text { information to the specific decision } \\
\text { making needs of communities at } \\
\text { risk }\end{array}$ & $\begin{array}{l}\text { (i) Increased provision of feedback } \\
\text { to scientists on provided } \\
\text { information and continued } \\
\text { exchanges. } \\
\text { (ii) Overcome the obstacles to } \\
\text { community level access and use of } \\
\text { climate information, through } \\
\text { participatory processes bringing } \\
\text { together providers of climate } \\
\text { information with communities at } \\
\text { risk }\end{array}$ \\
\hline
\end{tabular}

Shift from a mindset of Response to one of Preparedness through use of

(2) Mindset (no tradition of disaster preparedness and prevention among policy-makers, current paradigm of response)

forecast (understanding that

climate risk can be managed);

Managers of the Red Cross Disaster

Relief and Emergency Fund (DREF

convinced to release funds ex-ante of floods' onset based on seasonal

climate forecast.

No-regret strategies implemented by Red Cross: win-win strategy, effective way of placing loss-minimizing bet on probabilistic forecast

(3) Technical (content of forecasts unintelligible to decision makers)
2008 forecast timely (adequate lead time), contextual, and confident
Early warning-early action not systematic; funding of emergency appeal too little, too late; absence of international funding frameworks for forecast-based disaster management

No clearly defined thresholds of intervention, or chain of command to carry out early actions following forecasts (i) Systematize early action through the development of standard operating procedures, clearly assigning roles and responsibilities for action.

(ii) Develop international funding framework for forecast-triggered disaster management

Define clear thresholds of intervention, linking early actions to specific early warnings for relevant hazards probabilities of occurrence

Render climate forecasts less technical and jargon-filled, more understandable to users untrained in climate science, through detailed, clear forecast commentary in lay language; establish help desks. Build capacity of users to absorb forecasts and understand their uses/limitations through

Low capacity of users to understand user-scientist trainings; initiative and use forecasts

mostly urgent at national level to enable meaningful Early warning-early action at the community level

Limited forecasting skill over West Africa render current seasonal forecast irrelevant to decision

Realization that existing seasonal forecasts over West Africa provide information useful for disaster managers (e.g., likelihood of above-normal rainfall over the course of the season)
(4) Scientific (low skill level)

making needs of community-level

stakeholders; climate forecasts unable to respond to key information needs of end users in the region (e.g., onset of rainy season, rainfall distribution across season); regional climate research not driven by the information needs of decision makers

Use of existing community-level capacity (Red Cross volunteers,

(5) Limited capacity to act on forecasts solidarity groups at community level) to disseminate early warnings to communities at risk
In context of low human development, very limited capacity to act on seasonal forecast information
Decision maker needs to inform future regional climate research (user-driven research), namely on:

(a) threshold identification and probabilistic representation using terciles ("above normal" does not enable decision making)

(b) additional geographic precision

(c) intraseasonal extremes distribution

Supplement seasonal warnings with accompanying measures that enable communities to act on received information, adopt behavioral change, and increase their resilience to forecast hazards 
Table 1: Continued.

\begin{tabular}{|c|c|c|c|}
\hline Obstacle type & Achievements & Remaining obstacles & Recommendations \\
\hline (6) Low trust in forecasts & $\begin{array}{l}\text { A consensus-based confident } \\
\text { forecast (high probabilities) } \\
\text { inspired confidence in the climate } \\
\text { science to inform decision making }\end{array}$ & $\begin{array}{l}\text { This time the high probabilities for } \\
\text { above normal rainfall announced in } \\
\text { the forecast materialized } \\
\text { themselves; in the future when } \\
\text { probability level is invalidated will } \\
\text { the same trust remain? Is there } \\
\text { enough understanding among Red } \\
\text { Cross decision makers about the } \\
\text { uncertainties inherent in the } \\
\text { forecasting process? }\end{array}$ & $\begin{array}{l}\text { (i) Better explanation of the science } \\
\text { and limits of climate forecasting } \\
\text { (and the uncertainties involved in } \\
\text { the process of climate forecasting) } \\
\text { to develop trust. } \\
\text { (ii) Participatory, sustained and } \\
\text { reiterated workshops explaining, to } \\
\text { regional, as well as national and } \\
\text { community-level end stakeholders } \\
\text { uses of climate information }\end{array}$ \\
\hline
\end{tabular}

that suggests that, in their current form, seasonal forecasts are best able to inform decision making at the regional and national levels, but not to lead to useful behavioral change in communities at risk. The bottlenecks to climate information access and use beyond the regional and national levels remain and will require more focused efforts for climate information to be relevant and accessible to community-level stakeholders.

5.5. Summary of Findings. Most obstacles to seasonal forecast use remain in place even now. The packaging of the seasonal forecast is far from ideal, capacity to absorb information remains low, procedures and donors are still focused more on response than prevention. In 2008, the strong confident signal for likely above-normal rainfall and the presence of an in-house climate information translator and of an institutional champion open to innovation allowed for the seasonal forecast to be transmitted and acted on by the Red Cross. These conditions are not guaranteed to ensure ongoing progress unless sustained efforts are maintained to turn early warnings into early actions through standard practice-not just within IFRC and other humanitarian organizations, but also in the climate-meteorological community at large, and among donors.

The Red Cross in West Africa used a seasonal forecast to inform its disaster planning in 2008 in ways that saved lives, preserved livelihoods, and increased the resilience of communities at risk. This experience teaches that the distance between the climate science community and humanitarians can be bridged to generate positive outcomes for vulnerable populations, provided that there exist the following.

(1) A community of climate information providers ready to engage with users and respond to their information needs;

(2) a drive among humanitarian workers, and more generally, end users, to access and understand climate information and act upon it when there is a sufficiently strong signal;

(3) a disaster management framework (including the donor community) that facilitates a shift from response to preparedness, with mechanisms to mobilize resources for loss-reducing ex-ante measures at various timescales;

(4) community relays able to take the information to people at risk in effective ways.

This successful example of ex-ante flood management was stimulated through capacity building and institutional investments, new partnerships, and sustained user-scientist dialogues. These are important lessons about constraints to climate information use in Africa.

The results presented in this article are only suggestive; a thorough evaluation of the early warning-early action approach that started in 2008 is needed, one that will require longer time series and more rigorous impact assessments. But the Red Cross' 2008 flood management experience in West Africa demonstrates what can happen when a seasonal rainfall forecast, one that is confident, and timely, is duly accessed, understood, trusted and acted on by decision makers. In so doing, it also provides a valuable illustration of the applications that can be made of probabilistic seasonal forecasts (notably through no-regret strategies), with positive impacts for communities at risk.

\section{Acknowledgments}

The authors thank the following persons for their contributions to the innovations described in this article: Bhupinder Tomar, Peter Rees, Alassan Senghore, Norbert Allale, Jerry Niati, Mbalo Thioune, Bess Cisse, Aita Sarr Cisse, and Papa Mbagnick Diop. Due thanks also go to all participating institutions: the International Federation of the Red Cross-West and Central Africa Zone Office (IFRC), the Red Cross/Red Crescent Climate Centre, the International Research Institute for Climate and Society (IRI), the African Center for Meteorological Applications to Development (ACMAD), and AGRHYMET. Columbia University and Red Cross/Red Crescent Climate Centre Young Scholars program was funded by a grant/cooperative agreement from the National Oceanic and Atmospheric Administration (NA07GP0123 and NA050AR4311004). The views expressed herein are those of the authors and do not necessarily reflect the views of the IFRC, Red Cross/Red Crescent Climate Centre, NOAA. or any of their subagencies. 


\section{References}

[1] Food and Agricultural Organization of the United Nations, FAO Statistical Yearbook 2009, Rome, Italy, 2009.

[2] A. Dai, P. J. Lamb, K. E. Trenberth, M. Hulme, P. D. Jones, and P. Xie, "The recent Sahel drought is real," International Journal of Climatology, vol. 24, no. 11, pp. 1323-1331, 2004.

[3] M. Hulme, "Climatic perspectives on Sahelian desiccation: 1973-1998," Global Environmental Change, vol. 11, no. 1, pp. 19-29, 2001.

[4] M. Pelling and B. Wisner, Disaster Risk Reduction: Cases from Urban Africa, Earthscan, 2009.

[5] K. Diagne, "Governance and natural disasters: addressing flooding in Saint Louis, Senegal," Environment and Urbanization, vol. 19, no. 2, pp. 552-562, 2007.

[6] United Nations Development Program (UNDP), Human Development Report 2007/2008, Fighting Climate Change: Human Solidarity in a Divided World, New York, NY, USA, 2008.

[7] United Nations International Strategy for Disaster Reduction (UNISDR), Terminology on disaster risk reduction, 2009, http://www.unisdr.org/eng/terminology/terminology-2009eng.html.

[8] L. J. Ogallo, P. Bessemoulin, J. P. Ceron, S. J. Mason, and S. J. Connor, "Adapting to climate variability and change: the climate outlook forum process," The Journal of the World Meteorlogical Organization, vol. 57, no. 2, pp. 93-102, 2008.

[9] P. Suarez, "Linking climate knowledge and decisions: humanitarian challenges," The Pardee Papers 7, 2009.

[10] E. Archer, E. Mukhala, S. Walker, M. Dilley, and K. Masamvu, "Sustaining agricultural production and food security in Southern Africa: an improved role for climate prediction?" Climatic Change, vol. 83, no. 3, pp. 287-300, 2007.

[11] A. G. Patt, L. Ogallo, and M. Hellmuth, "Sustainability: learning from 10 years of climate outlook forums in Africa," Science, vol. 318, no. 5847, pp. 49-50, 2007.

[12] C. Vogel and K. O'Brien, "Who can eat information? Examining the effectiveness of seasonal climate forecasts and regional climate-risk management strategies," Climate Research, vol. 33, no. 1, pp. 111-122, 2006.

[13] A. Patt and C. Gwata, "Effective seasonal climate forecast applications: Examining constraints for subsistence farmers in Zimbabwe," Global Environmental Change, vol. 12, no. 3, pp. 185-195, 2002.

[14] A. Tall, "Climate forecasting to serve communities in West Africa," Procedia Environmental Sciences, vol. 1, no. 1, pp. 421$431,2010$.

[15] C. Roncoli, K. Ingram, and P. Kirshen, "Reading the rains: local knowledge and rainfall forecasting in Burkina Faso," Society and Natural Resources, vol. 15, no. 5, pp. 409-427, 2002.

[16] Direction Nationale de la Meteorologie du Mali (DNM), "November 2005: assistance meteorologique operationnelle au monde rural au mali: développement acquis-perspectives," Mali National Meteorological Office Report 35, 2005.

[17] K. O’Brien, L. Sygna, L. Naess, R. Kingamkono, and B. Hochobeb, Is Information Enough? User Responses to Seasonal Climate Forecasts in Southern Africa. Report to the World Bank, Adaptation to Climate Change and Variability in Sub-Saharan Africa, Phase II, CICERO, 2000.

[18] K. O'Brien and C. Vogel, Coping with Climate Variability: the Use of Seasonal Climate Forecasts in Southern Africa, Ashgate, Burlington, Vt, USA, 2003.

[19] G. Ziervogel and R. Calder, "Climate variability and rural livelihoods: assessing the impact of seasonal climate forecasts in Lesotho," Area, vol. 35, no. 4, pp. 403-417, 2003.
[20] C. T. West, C. Roncoli, and F. Ouattara, "Local perceptions and regional climate trends on the Central Plateau of Burkina Faso," Land Degradation \& Development, vol. 19, no. 3, pp. 289-304, 2008.

[21] M. E. Hellmuth, A. Moorhead, M. C. Thomson, and J. Williams, Eds., Climate Risk Management in Africa: Learning from Practice, Climate \& Society Series no. 1, International Research Institute for Climate and Society (IRI), Columbia University, New York, NY, USA, 2007.

[22] K. T. Ingram, M. C. Roncoli, and P. H. Kirshen, "Opportunities and constraints for farmers of west Africa to use seasonal precipitation forecasts with Burkina Faso as a case study," Agricultural Systems, vol. 74, no. 3, pp. 331-349, 2002.

[23] P. C. S. Traoré, M. Kouressy, M. Vaskmann et al., "Climate prediction and agriculture: what is different about SudanoSahelian West Africa?" in Climate Prediction and Agriculture: Advances and Challenges World Meteorological Organization, M. V. K. Sivakumar and J. Hansen, Eds., pp. 189-203, 2007.

[24] T. Grothmann and A. Patt, "Adaptive capacity and human cognition: the process of individual adaptation to climate change," Global Environmental Change, vol. 15, no. 3, pp. 199213, 2005.

[25] African Center for Meteorological Applications to Development (ACMAD), Seasonal forecast of precipitation bulletin for West Africa, Chad and Cameroon for July-August-September 2008.

[26] O. Ndiaye, J. Hansen, and A. Robertson, "Prediction of rainfall frequency and related quantities in West Africa," Case Paper, International Research Institute for Climate and Society (IRI), Columbia University, New York, NY, USA, 2008.

[27] African Center for Meteorological Applications to Development (ACMAD), Climate Watch Africa Bulletin no. 6, 2007.

[28] L. Braman, "Early warning, early action: an evaluation of IFRC West and central Africa zone flood preparedness and response," International Federation of the Red Cross and Red Crescent Societies (IFRC) Report 56, IFRC, 2009.

[29] International Federation of the Red Cross and Red Crescent Societies, "West and central Africa: flood preparedness emergency appeal,” Tech. Rep. MDR6100, IFRC, 2008.

[30] International Federation of the Red Cross and Red Crescent Societies, "Early warning-early action: the experience of West African floods, 2007-2008," International Federation of the Red Cross and Red Crescent Societies (IFRC) and Red Cross/Red Crescent Climate Centre Climate Risk management Case Paper 6, 2009.

[31] A. Tall, "Bridging the gap between the climate science community and the IFRC West and Central Africa Zone Office," Report, International Federation of the Red Cross / Red Crescent Report, 2008.

[32] J. Niati, personal communication, 2009.

[33] M. Daly, "Translating climate information into action: considering next steps for early warning, early action in West and Central Africa," in Proceedings of the 3rd World Climate Conference, World Meteorological Organization, Geneva, Switzerland, 2009.

[34] Munich Climate Insurance Initiative, Draft Article for Risk Reduction and Insurance Mechanisms in the context of Adaptation to Climate Change For Party consideration in the Copenhagen negotiating text, 2010, http://www.climateinsurance.org/upload/pdf/20090410_draft_MCII_April_24_ submission.pdf. 

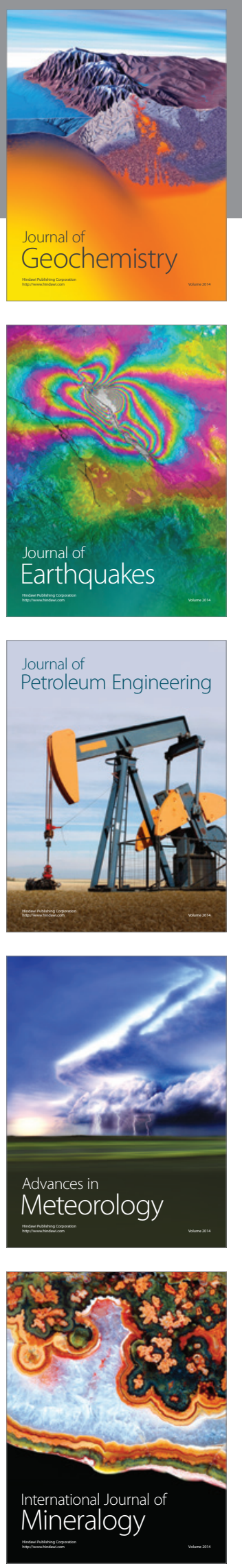
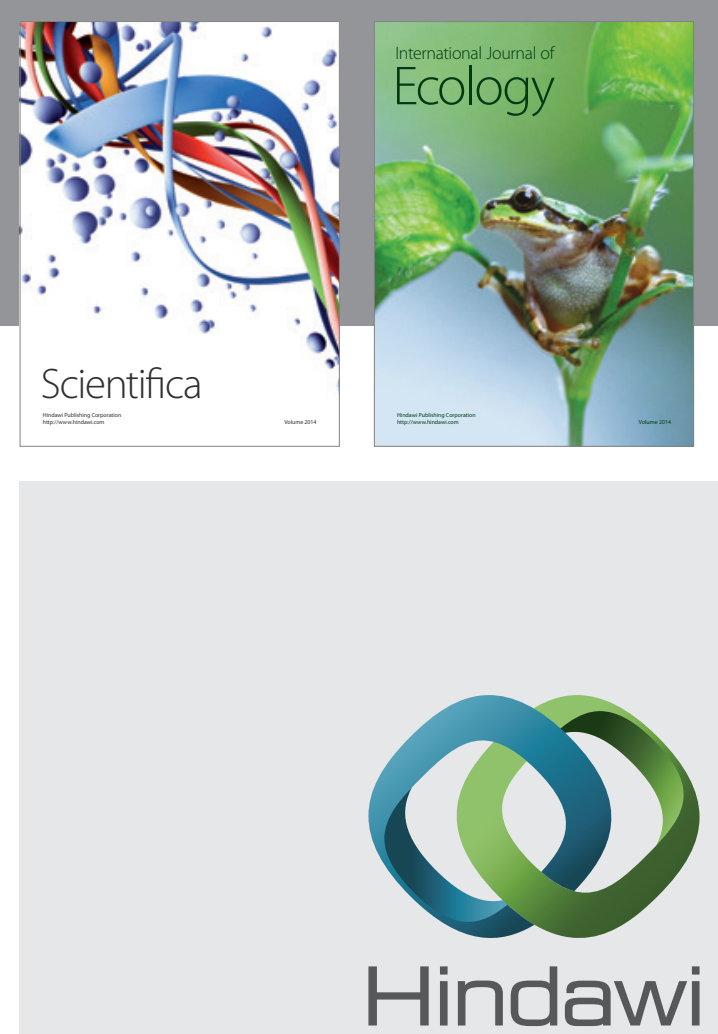

Submit your manuscripts at http://www.hindawi.com
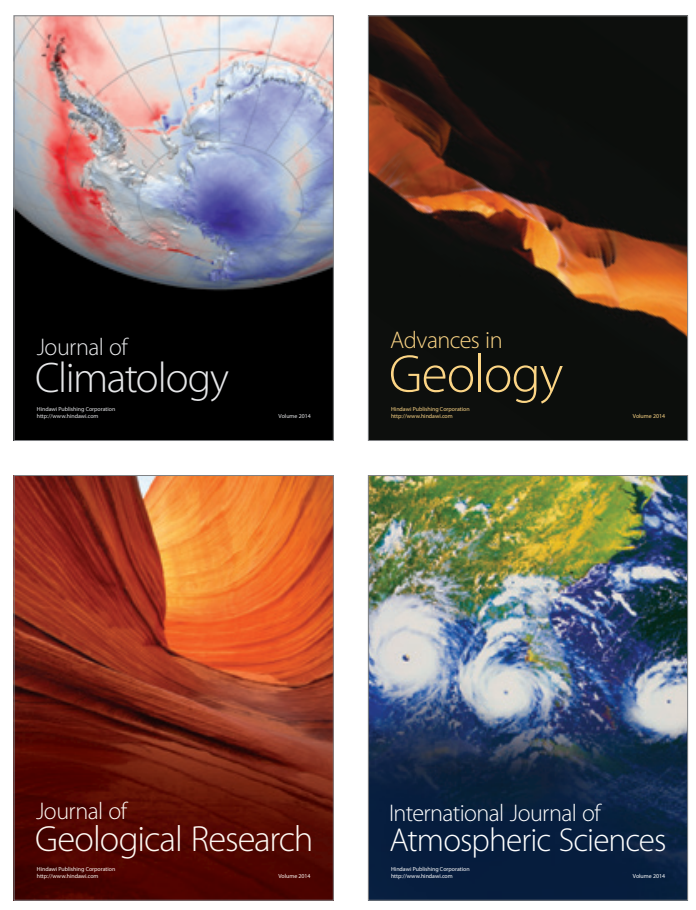
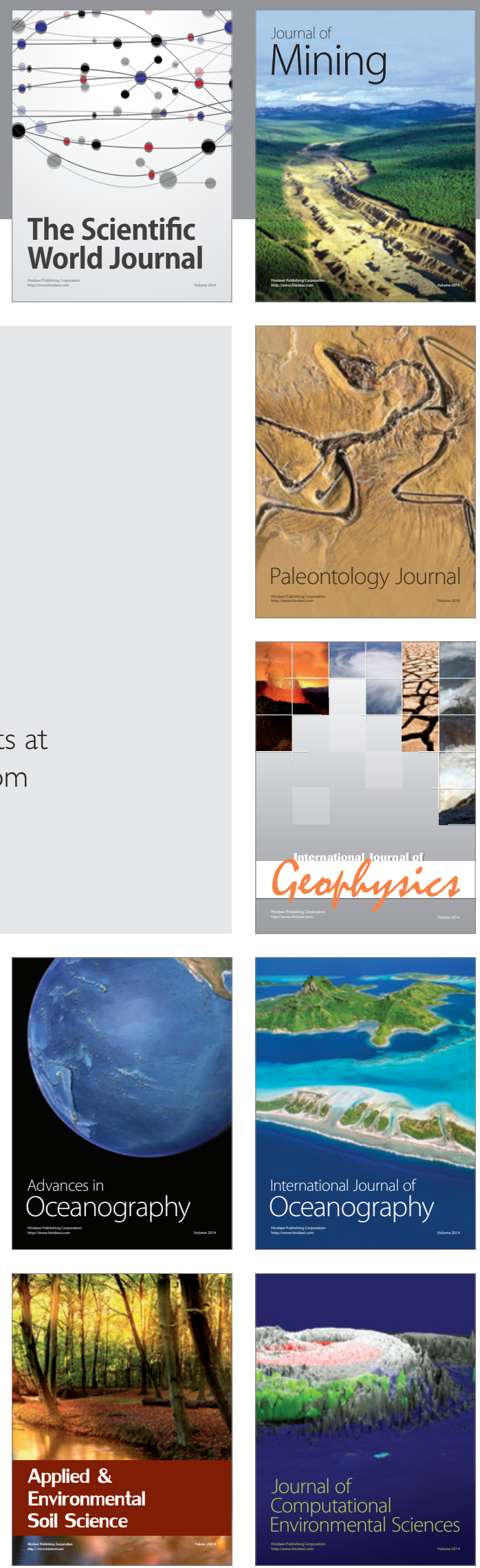